\title{
Correction to: Mixed-method tutoring support improves learning outcomes of veterinary students in basic subjects
}

María J. García-Iglesias ${ }^{1 *}$, Claudia Pérez-Martínez², César B. Gutiérrez-Martín ${ }^{3}$, Raquel Díez-Laiz ${ }^{4}$ and Ana M. Sahagún-Prieto ${ }^{4}$

\section{Erratum}

The original article [1] contained an error whereby Fig. 2a and b were mistakenly swapped with each other, and thus did not correspond to their correct respective sub-figures. The original article has been updated to include the correct configuration of Fig. 2a and b which can also be viewed ahead.

\begin{abstract}
Author details
'Department of Animal Health, Faculty of Veterinary Science, Institute of Biomedicine (IBIOMED), University of León, Campus de Vegazana, s/n, 24071 León, Spain. ${ }^{2}$ Department of Animal Health, Faculty of Veterinary Science, Institute of Biomedicine (IBIOMED), University of León, Campus de Vegazana, s/n, 24071 León, Spain. ${ }^{3}$ Department of Animal Health, Faculty of Veterinary Science, University of León, Campus de Vegazana, s/n, 24071 León, Spain. ${ }^{4}$ Department of Biomedical Sciences, Faculty of Veterinary Science, Institute of Biomedicine (IBIOMED), University of León, Campus de Vegazana, s/n, 24071 León, Spain.
\end{abstract}

Received: 7 February 2018 Accepted: 20 February 2018

Published online: 07 March 2018

\section{Reference}

1. García-Iglesias MJ, et al. Mixed-method tutoring support improves learning outcomes of veterinary students in basic subjects. BMC Vet Res. 2018;14:35.

\footnotetext{
* Correspondence: mjgari@unileon.es

${ }^{1}$ Department of Animal Health, Faculty of Veterinary Science, Institute of Biomedicine (IBIOMED), University of León, Campus de Vegazana, s/n, 24071 León, Spain

Full list of author information is available at the end of the article
} 


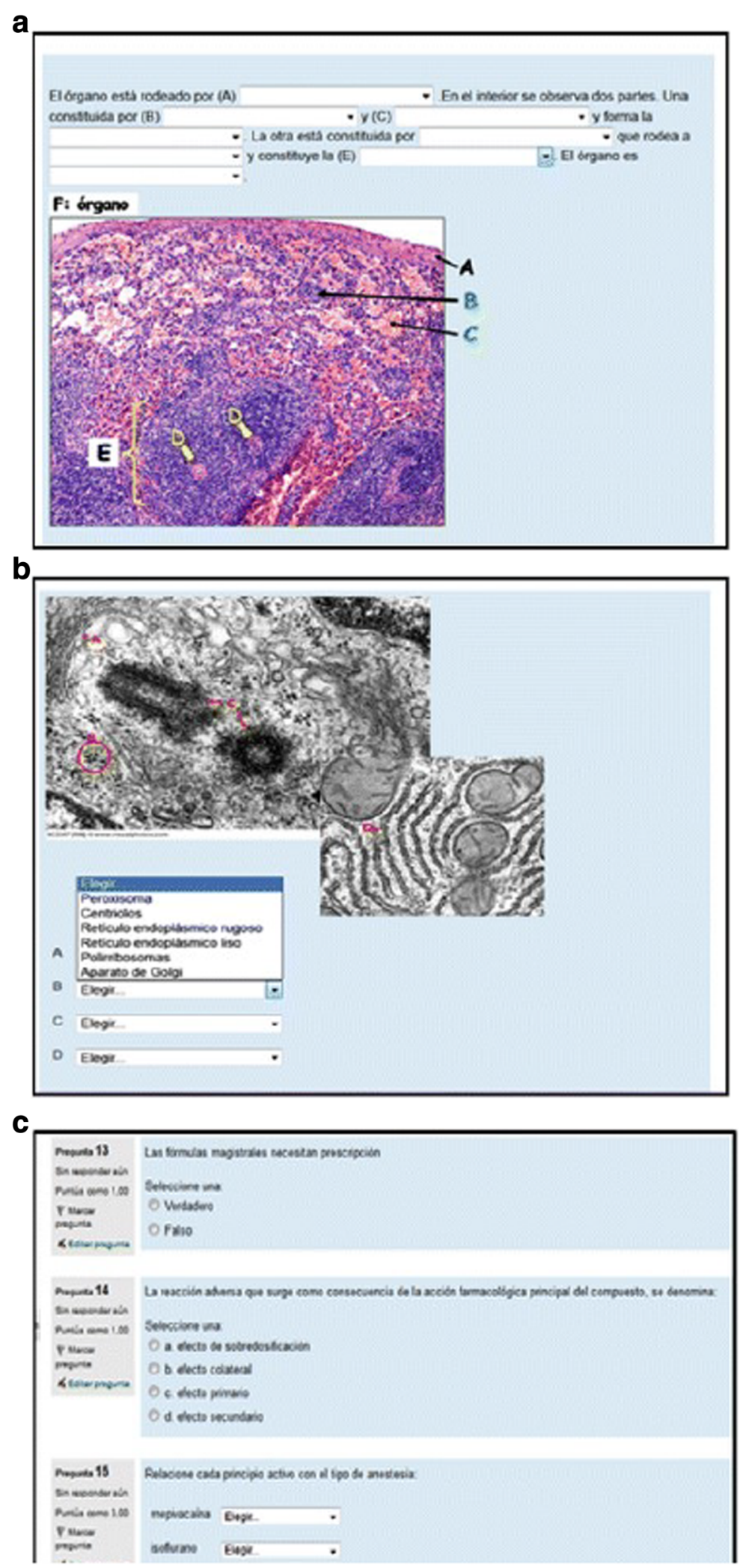

Fig. 2 Different types of online questionnaires. a Embedded answers (gap fill). b matching. $\mathbf{c}$ true/false, multiple choice and matching tests 